\title{
¿Autogestión dentro de la autonomía? \\ La experiencia de la cooperativa de cafeticultores \\ indígenas zapatistas Yochin Tayel Kinal
}

\section{Self-management within autonomy? \\ The experience of Yochin Tayel Kinal, an indigenous \\ Zapatista coffee cooperative}

\section{Mario Alberto Suárez Carrera ${ }^{1}$}

Resumen: En este trabajo se presentan algunos aspectos del desarrollo de una cooperativa de café integrada por productores indígenas afiliados al zapatismo en la "zona de conflicto" de Chiapas, en particular las dificultades para su autogestión en el contexto del proyecto de autonomía política y territorial encabezado por el EZLN, y de su estrategia de resistencia. Asimismo, se discute el problema de la aplicación de discursos emancipatorios — autonomía, autodeterminación y autogestión-y su alcance en los espacios sociales. Una

\footnotetext{
${ }^{1}$ Maestro en ciencias en Desarrollo Rural Regional por la Universidad Autónoma Chapingo. Colaborador de la asociación civil Guayacán. Temas de interés: desarrollo rural, comercio justo, producción y economía campesina, cafeticultura.

Correo electrónico: guayacan03@hotmail.com

Fecha de recepción: 2606 14; Fecha de aceptación: 2208 14.:
} 
cuestión central es: ¡cuál es el sujeto social de la autonomía? Para la reflexión se utiliza la perspectiva de análisis estructural, relacional, y la noción de campo de poder propuesta por Pierre Bourdieu, para concluir que en la práctica zapatista prevalece el concepto de "lo colectivo" como fuerza principal en sus relaciones. Palabras clave: campo de poder, cooperativa, autonomía, resistencia, zapatismo.

Abstract: This article introduces some issues concerning a coffee cooperative formed by indigenous Zapatista producers in the "conflicting area" of Chiapas, particularly the difficulties for its self-management process in the framework of the political and territorial project headed by EZLN, and its resistance strategy. The problem about the application of emancipation discourses — autonomy, self-determination, self-management- and its outreach in social spaces is also discussed. A core question is: Who is the social subject of autonomy? This approach draws from Pierre Bourdieu's perspective of structural and relational analysis and his notion of power field and concludes that the concept of the "collective" prevails in Zapatista practice as a main force in its relationships.

Keywords: power field, cooperative, autonomy, resistance, zapatismo. 


\section{Introducción}

Muchas cooperativas de cafeticultores en Chiapas, como en otras entidades productoras de café, han sido creadas como una de las estrategias del campesinado para enfrentar el deterioro experimentado bajo la actual fase de acumulación del capital. Y lo han hecho acoplándose a los resquicios que la economía de mercado no alcanza a cubrir —en tanto no sea suficientemente atractiva o rentable-, aprovechando también la creación de nuevos nichos de consumo que la globalización ha propiciado: los segmentos de consumidores de productos de comercio justo, alternativos, orgánicos, saludables, ecológicos o "amigables" con el medio ambiente. Tal es el caso de la cooperativa Yochin Tayel Kinal (YTK), ${ }^{2}$ que desde su conformación en el año 2000 como Sociedad de Producción Rural (SPR) ha venido participando hasta la fecha en casi todos los segmentos de la cadena productiva del café, desde la producción orgánica hasta el procesamiento y comercialización del grano. Los socios de YTK provienen de comunidades integradas a la región del Caracol 4, cuya sede se localiza en el ejido Morelia, del municipio oficial de Altamirano, Chiapas.

La adscripción de los socios y las unidades productivas de Yochin Tayel Kinal al movimiento zapatista como bases de apoyo (BAZ) es lo que le imprime a esta cooperativa sus rasgos particulares en cuanto a su dinámica organizativa, democracia interna, autonomía y redes de relaciones. Podemos así distinguir este tipo de organizaciones productivas de café en virtud de que

\footnotetext{
${ }^{2}$ Yochin Tayel Kinal (tzeltal): "Entrando al Trabajo en un Nuevo Amanecer".
} 
se desenvuelven dentro del contexto de un movimiento campesino en resistencia - cuyo concepto y práctica es uno de los materiales a analizar en este trabajo- - de aquellas que no han renunciado a la gestión de financiamientos o apoyos de instituciones oficiales, y cuyas prioridades y lógica se encuentran marcadamente dentro del terreno económico-productivo, o dentro de lo que, en los debates sobre el movimiento campesino en México, se daba en llamar "las luchas por la apropiación del proceso productivo".

No obstante que después de la irrupción zapatista de enero de 1994 se ha producido abundante literatura sobre el movimiento y sus causas e interpretaciones, no hay suficientes estudios específicos relacionados con las experiencias productivas y económicas zapatistas, así como con las dinámicas, prácticas y relaciones entre gobierno y gobernados al interior de los territorios autónomos controlados por las bases del EZLN; ${ }^{3}$ a mi parecer se requiere contar con más investigaciones y análisis que nos permitan acercarnos a la comprensión y “objetivación” de las bases materiales, económicas y productivas del proceso autonómico zapatista en curso. Lo que aquí presento pretende contribuir a ello.

Durante mi observación y acompańamiento del proceso organizativo y del funcionamiento de la cooperativa YTK fueron identificadas diversas problemáticas que se propusieron como pautas de investigación, ${ }^{4}$ entre ellas,

\footnotetext{
${ }^{3}$ Como lo han documentado, entre otros: Harvey, 2000; Gerber, 2004; Velasco, s/f.

${ }^{4}$ La colaboración del autor de este artículo en el proceso seguido por la cooperativa se desarrolló en el periodo 1999 a 2010, en tanto que la investigación formal se llevó a cabo en 20102012 como parte del programa de maestría en ciencias en Desarrollo Rural Regional por la Universidad Autónoma Chapingo.
} 
las dificultades y contradicciones para hacer compatible un proyecto sectorial —el de la cooperativa YTK y específicamente la cafeticultura - con un proyecto más amplio, enmarcado dentro de las estrategias de resistencia en el espacio autónomo zapatista.

Otra de las temáticas observadas ha sido el problema de la aplicación y práctica de conceptos y discursos emancipatorios tales como autonomía, autodeterminación y autogestión en un movimiento sociopolítico como el zapatista, y su alcance en los diversos espacios sociales como el constituido por la cooperativa YTK. La forma en que se aplica la democracia directa, horizontal, y el "mandar obedeciendo" que se propugna desde el movimiento zapatista. Aquí, una de las preguntas centrales es: ¿Cuál es el sujeto social de la autonomía: el individuo, la unidad doméstica, la comunidad, las agrupaciones sectoriales, el colectivo zapatista en su totalidad?5

En otro sentido, sobre el proceso mediante el cual se han institucionalizado las autoridades zapatistas de gobierno - Juntas de Buen Gobierno, JBG-, en el que se observan contradicciones entre su estructura civil y su relación supeditada a la estructura militar, así como sus relaciones con sus propias bases, con los agentes externos y la sociedad civil, y con las instituciones oficiales, me interesó profundizar en el conocimiento y analizar las prácticas y formas mediante las cuales se enmarca la experiencia de la cooperativa YTK en su dinámica interna, y en sus relaciones con la estructura de gobierno zapatista, con la autonomía

\footnotetext{
${ }^{5}$ Como lo propone N. Harvey, el movimiento zapatista expresa la voluntad de "El derecho a
} tener derechos y la construcción de ciudadanía" (Harvey, 2000). 
y sus estrategias de resistencia, así como con las instituciones del Estado y la "globalización".

\section{YTK en el campo sociopolítico zapatista. Algunos conceptos y consideraciones teóricas}

Durante el desarrollo de las actividades de YTK hemos observado un conjunto de prácticas y relaciones entre los distintos agentes que participan en el campo sociopolítico zapatista. Y es dentro de este $\operatorname{campo}^{6}$ que se desenvuelve la cooperativa YTK como uno de los agentes que participa y “juega” en él, haciendo uso de sus recursos y estrategias para tratar de consolidar su posición. A su vez, la propia cooperativa YTK se puede observar como un sistema de posiciones sociales que nos permitirían distinguir, en el microcosmos de la cooperativa, lo que conformaría un subcampo o arena con autonomía relativa, ya que opera con su propia lógica y con sus redes de relaciones dentro de los límites y condicionamientos que le impone su pertenencia al campo zapatista, aun y cuando permitirían un sutil juego de posiciones que, sin cuestionar abiertamente las posiciones de poder, reflejarían la existencia de disentimientos o posturas diferenciadas entre los agentes.

Tales agentes están conformados por los integrantes de las JBG, la dirección del EZLN, los mandos militares regionales que operan asesorando a las juntas, la así llamada "sociedad civil" — diversas ong, organismos de ${ }^{6}$ P. Bourdieu (Bourdieu y Wacquant, 1995) plantea la noción de espacio social que está formado por un conjunto de campos de "juego" con relativa autonomía que no podrían reducirse a la lógica de sociedad única. Ésta y otras nociones formuladas por el sociólogo francés guiaron el trabajo de investigación del que se deriva este artículo. 
cooperación internacional y de comercio justo, compradores de café producido por zapatistas-, la mesa directiva de la propia cooperativa, los representantes regionales de los productores, los coyotes o intermediarios locales, el organismo de certificación de la producción ecológica de café (Certimex, S. C.).

Intentaré contextualizar estas prácticas y relaciones dentro de los debates y consideraciones teóricas elaboradas — algunas de ellas — en referencia explícita al zapatismo.

En contraste con los teóricos de los nuevos movimientos sociales, que sostienen que la acción social se presenta como una respuesta en el ámbito cultural, Atilio Boron (2001) argumenta desde la teoría política marxista que el neozapatismo es una expresión de la lucha de clases y de los enfrentamientos globales contra el neoliberalismo, pues “...se trata del primer movimiento de masas que convoca a una resistencia global, armada y sin cuartel contra el neoliberalismo"; en este sentido se trataría de un movimiento antisistémico en el que, desde esta perspectiva, forma parte de las luchas internacionales contra el capitalismo a partir de la estructura de la sociedad en clases sociales, “...dada la clara inspiración que la dirigencia zapatista encuentra en el materialismo histórico" (Boron, 2001: 9). No obstante, al caracterizar de esta manera al zapatismo, este autor reclama críticamente a su dirigencia lo que a su juicio - lo que en este aspecto puntual compartimos - es una utilización equívoca de conceptos como democracia y sociedad civil, pues son contradictorios con su proyecto político. 
Y ciertamente, en lo que toca al tema de la sociedad civil, o "tercer sector", 7 que de manera muy generalizada se asocia con los organismos no gubernamentales u organismos civiles, y reiteradamente se le apela desde diversos frentes políticos y corrientes de opinión, nos encontramos ante un concepto sumamente elástico, en el que puede incluirse a casi cualquier grupo social dotado de agencia o interés colectivo en actuar social y políticamente en determinados espacios y problemáticas de la sociedad.

La forma en que el zapatismo empezó a diseñar y conformar sus espacios de influencia, es decir los territorios, nos muestra como "...la creación de la territorialidad genera una geografía del poder caracterizada por la desigualdad, la fragmentación, la tensión y el conflicto" (Montañez y Delgado, 1998: 125). Así, por ejemplo, los imperativos de la defensa del territorio invocan la necesidad de producir mecanismos y estrategias de soporte material, como es el caso de las contribuciones e impuestos zapatistas; y político-territoriales, como son la autonomía y la resistencia.

El concepto autonomía se opone a la heteronomía - entendida como la voluntad determinada desde el exterior al sujeto individual o colectivo- y consiste en la salvaguarda de una población, en un espacio determinado — los caracoles y municipios zapatistas — de derechos jurisdiccionales de libre determinación en todos los asuntos públicos que conciernen a esa

\footnotetext{
7 “...ese conjunto de estructuras y espacios a los que [Gramsci] denominó 'sociedad civil' ". Óscar Ochoa González, 2003, "Conversando sobre Gramsci, sociedad civil y hegemonía", Centro de Investigación y Desarrollo de la Cultura Juan Marinelo, La Habana, Cuba, en http:// www.archivochile.com/Ideas_Autores/gramscia/s/gramscisobre0015.pdf
} 
colectividad. La expresión de la autonomía es el principio "mandar obedeciendo", institucionalizado con la creación de las Juntas de Buen Gobierno en los caracoles zapatistas.

Podríamos caracterizar a la resistencia neozapatista como el conjunto de prácticas predominantemente no violentas frente a “...condiciones específicas de dominación que ponen en riesgo o vulneran garantías para la libertad y justicia de las comunidades" (Molina, 2004: 146); como estrategias de acción colectiva cotidiana para oponerse y contrarrestar el statu quo. En el ideario zapatista, la resistencia es un conjunto de medidas de defensa contra la dominación que apela a valores como la dignidad, ${ }^{8}$ la economía moral, los derechos de los pueblos originarios. A diferencia de la rebelión, que consiste en estallidos sociales acompañados de violencia ante demandas o agravios específicos, y que a menudo está localizada espacial y temporalmente. En el caso zapatista, con la irrupción de enero de 1994, la rebelión antecedió a la resistencia que actualmente se practica desde los territorios autónomos. La resistencia zapatista alude al desconocimiento de los tres niveles oficiales de gobierno y al rechazo de los programas, proyectos y apoyos de los mismos.

En un sentido más amplio, que es el que estamos considerando en este trabajo, entendemos el proceso de institucionalización como la implantación e interiorización, por parte de las bases de apoyo zapatista, de las estructuras de gobierno — las JBG-, las formas de organización para el trabajo y la cooperación, la vigilancia, la educación, etc., dentro del espacio en que se ${ }^{8}$ En "La revuelta de la dignidad [...], el núcleo de lo nuevo del zapatismo es el proyecto de cambiar el mundo sin tomar el poder" (Holloway, 2001a: 174, cit. por Boron, op. cit.). 
desenvuelve la cooperativa YTK — la región del Caracol 4 y su estructura de gobierno-. En este proceso también intervienen las estrategias de reproducción que emplean los agentes dentro de dicho espacio, y las formas de coerción que se ejercen desde las posiciones dominantes. La institución resultante de dicho proceso es, finalmente, la “...estructura organizativa e instancia reguladora de las prácticas" sociales (Bourdieu, 1977: 117).

\section{El contexto geográfico y territorial}

La localización de las unidades productivas de YTK, lejos de constituir un área compacta, está conformada por múltiples puntos diseminados en una considerable extensión territorial que se encuentra imbricada dentro de los municipios oficiales de Altamirano, Chilón, Ocosingo, Oxchuc y San Juan Cancuc, por lo que no podría describirse como una región fisiográfica homogénea aunque comparten, eso sí, algunas características —clima, suelos, etc.- que posibilitan utilizar los recursos productivos para el cultivo del café.

La distribución territorial de las unidades productivas de la cooperativa obedece, en buena medida, a la lógica y a los criterios de regionalización de los municipios autónomos rebeldes zapatistas (Marez), y de las regiones "integradoras" conocidas como "Aguascalientes" hasta el año 2003, posteriormente llamados "Caracoles". Dado que tales criterios no utilizan parámetros geográficos y/o económicos para delimitar sus regiones — a diferencia de la lógica oficial—, sino políticos y de pertenencia 
o de identidad como comunidades de base zapatista, se nos presenta un complicado polígono difícil de describir y caracterizar (ver mapa anexo).

A más de 10 años de la creación de los caracoles y las JBG en 2003, los municipios autónomos rebeldes zapatistas y las propias Juntas de Buen Gobierno han llevado a cabo un proceso de institucionalización de la autonomía, del gobierno y de la resistencia, que conduce a establecer determinados campos de poder y ciertas pautas en las relaciones con otros agentes sociales, como es el caso de la cooperativa YTK. Es a partir de este reordenamiento territorial, jurisdiccional y administrativo en el que se echan a andar - o se validan- diversas iniciativas como las que dan origen a la cooperativa YTK. Todo lo anterior obliga a introducirnos en la discusión acerca de las ideas de territorio, región y gobierno en el zapatismo, así como en la concepción y práctica de la resistencia, para tratar de caracterizarla frente a las interrogantes de cómo, frente a qué y con qué medios se resiste.

Por otra parte, es a consecuencia del levantamiento armado de 1994 que reemerge con más fuerza el término "sociedad civil", al tiempo que se observa una multiplicación de grupos, colectivos y organismos civiles, surgidos muchos de ellos al calor del movimiento zapatista, al grado que algunos analistas llegarían a considerarla como el "tercer poder". Como parte de dicha proliferación de organismos civiles, desde su formación la cooperativa YTK ha sido acompañada en su trayectoria por la sociedad civil. 
Enseguida pasaré a exponer algunas de las características mediante las cuales se desarrolla la actividad productiva de las unidades de producción que integran la cooperativa.

\section{El cultivo de café en la zona de influencia de YTK}

El cultivo de café se mantiene entre numerosas familias —zapatistas y no zapatistas - de la región en virtud de que representa, de la misma forma que lo hace la posesión de ganado, una modalidad de ahorro para la economía campesina que genera ingresos monetarios complementarios para su reproducción. Y en este sentido las unidades productivas, por medio de la mano de obra predominantemente familiar, le dedican a la actividad más o menos intensidad de acuerdo con las fluctuaciones de los precios regionales del café. En el caso de los campesinos zapatistas que producen café, muchos de ellos lo hacen a partir de los terrenos ocupados desde 1994 en los que ya había explotaciones cafetaleras a cargo de propietarios privados de fincas; esto explica que la mayor parte de las plantaciones que ahora se aprovechan son en su mayoría viejas y poco productivas. ${ }^{9}$ Sólo en una pequeña proporción se han establecido nuevas y pequeñas plantaciones en los nuevos centros de población fundados por la reforma agraria zapatista, como en el caso de los poblados 10 de Abril, 7 de Enero, 8 de Marzo, $1^{\circ}$ de Diciembre, Lucio Cabañas.

\footnotetext{
${ }^{9}$ Los rendimientos estimados de café pergamino por unidad de superficie (hectárea) fluctúan de 6 a 8 bultos — de 360 a $480 \mathrm{~kg}$ — entre las unidades productivas de YTK.
} 
Las condiciones agroecológicas de las cinco regiones (ver mapa anexo) donde se encuentran las unidades productivas que pertenecen a la cooperativa YTK, si bien tienen algunas similitudes en cuanto a la tecnología utilizada, también presentan algunas diferencias topológicas, altitudinales y climáticas, que explican el hecho de que el grano cosechado tenga características físicas y organolépticas heterogéneas. Como muchas otras zonas cafetaleras de Chiapas, el sistema empleado se dice rusticano o de montaña, que es el modelo más simple, muy similar a las condiciones donde se encuentra el café en su estado silvestre, en el que predominan diferentes tipos de vegetación natural, así como el sistema de policultivo tradicional; se trata de plantaciones de café bajo sombra en cuya composición existe una gran diversidad de especies vegetales que incluyen elementos tanto de vegetación natural — primaria y secundaria - como cultivada — especies nativas e introducidas, por ejemplo el árbol inga o chalum.

Con variaciones de altura sobre el nivel del mar que van desde 700 metros en la región de La Montaña — municipio oficial de Chilón, municipio autónomo Comandante Ramona a partir de 2008, de acuerdo con la regionalización zapatista-, hasta 1,450 msnm en algunos puntos del municipio de San Juan Cancuc, el grano de café obtenido de las zonas más bajas (La Montaña), aunque madura más tempranamente, tiene dimensiones más pequeñas y menor grado de acidez, en comparación con los granos más grandes cosechados en Cancuc que, en estricto sentido, corresponden a un café de altura. En las cinco regiones, los productores realizan la primera parte del proceso del 
grano por la vía húmeda, que consiste en lavar, despulpar y secar al sol hasta obtener el café llamado pergamino. Al igual que a la totalidad del café que se produce en el país, al producto se le clasifica como prima lavado en oro para fines de exportación, y en la clasificación internacional —igual que a todo el café mexicano- como "Otros Suaves" (Organización Internacional del Café, ICO, por sus siglas en inglés).

\section{La particularidad de las cooperativas zapatistas}

La pertenencia de los socios de YTK al movimiento zapatista en su calidad de bases de apoyo o cooperantes $^{10}$ es el sello distintivo de esta cooperativa; como afirma Alfredo, presidente fundador: "nosotros no somos como las otras organizaciones del café, que todo les da el gobierno, hasta el precio de sus cafés". ${ }^{11} \mathrm{Se}$ refiere a la mayoría de las organizaciones de pequeños productores (OPP) del "sector social" que operan en Chiapas, y que han tenido un crecimiento significativo en las últimas décadas (“desde 1980", Renard, 1999), muchas de ellas vinculadas a los modelos de producción ecológica y de comercio justo. Dicha pertenencia, aunque no lo expresa Alfredo, también incluye a las otras cooperativas de productores de café que se desenvuelven dentro de los espacios del zapatismo, como son Mut Vitz, ${ }^{12}$ Yachil Xojoval Chulchan, y Ssit Lequil Lum.

Para la conformación de las cooperativas de café se pusieron en juego las prioridades de la estrategia del movimiento zapatista, que daban

\footnotetext{
${ }^{10}$ En los espacios autónomos se designan de esta manera a las familias integrantes de las BAZ.

${ }^{11}$ Entrevista al presidente fundador de la cooperativa, Altamirano, 14 de marzo de 2009.

${ }^{12}$ Esta cooperativa dejó de operar en el año 2007.
} 
preponderancia a la lucha política y a la resistencia como prácticas necesarias para contrarrestar, desde sus espacios, la fuerza del Estado. Las necesidades materiales y económicas de las bases de apoyo se situaron, de ese modo, en un segundo plano que, en todo caso, habrían de ser atendidas por la cooperación solidaria de la sociedad civil. Es por eso que la dirigencia zapatista apelaba a las acciones de suplencia - lo que no hace el gobierno lo tiene que hacer la sociedad civil— de los organismos nacionales e internacionales que hacen suya la bandera zapatista.

\section{La experiencia de YTK en el comercio justo}

La inserción de la cooperativa en el esquema del comercio justo, o en una de sus variantes, ${ }^{13}$ se alcanzó durante el ciclo 2004, a partir de que se logró consolidar una base más o menos amplia de unidades productivas y con ello un potencial de acopio de café susceptible de comercializarse en el mercado de exportación. Para ello sería importante la colaboración de esos organismos de la sociedad civil a los que se hace referencia en los párrafos anteriores.

Por una parte teníamos a ong locales, como Guayacán, A. C. que había apoyado con aspectos técnicos y de capacitación a los socios y representantes de la cooperativa desde su creación, y por otro a diversos colectivos

${ }^{13}$ En el comercio justo la expresión "precio justo alude a aquel que permite cubrir los costes de producción, sufragar las necesidades básicas [de los productores] y obtener un remanente para invertir, y que se mantiene estable... tendencia a disminuir la dependencia del comercio internacional [el predominante, es decir, el comercio injusto] fortaleciendo su posición en el mercado local y garantía de mantenimiento de la soberanía alimentaria de la zona productora" (Roberto Bermejo, Realidades y tendencias del comercio justo, Cuadernos Bakeaz, núm. 33, junio de 1999). Al comercio justo también suele denominarse como comercio alternativo, equitativo, etcétera. 
nacionales e internacionales interesados en colaborar con la causa zapatista, entre otras acciones, por medio de la compra de productos de las BAZ. Ya desde la experiencia de Mut Vitz se había creado una red de colectivos, como la Red Prozapa ${ }^{14}$ que había iniciado la compra de café de esta cooperativa desde el año 1998. De tal suerte que, sumándose los factores no convencionales del mercado de la oferta-demanda-solidaridad —en lo que podríamos resumir los principios generales del comercio justo-, se abrió la puerta para comprar el café que producía y acopiaba YTK. Se establecería entonces la conexión entre los productores de YTK y el mercado de exportación hacia los nichos del comercio justo facilitada por la ong local que fungiría como una especie de grupo asesor de la cooperativa.

Entrar al comercio justo o alternativo significó para las familias asociadas a YTK mejorar sus ingresos por la venta de café en virtud del sobreprecio pagado por las organizaciones de Red Prozapa, en contraste con los precios habituales pagados por los coyotes locales. Una de las vías para acceder a estos sobreprecios era el valor agregado, ya que se trataba de un producto ecológico —orgánico — certificado. Y la otra era el valor simbólico — traducido en dinero- en virtud de que era un producto que provenía de los espacios y de la lucha zapatista, con la que se identifican los colectivos de la mencionada Red; tal sobreprecio representa una contribución adicional que va más allá de la mera relación comercial, e intenta fortalecer el proceso autonómico zapatista.

\footnotetext{
${ }^{14}$ Red integrada por colectivos europeos y de EE UU afines al zapatismo.
} 
Para la mesa directiva implicó la necesidad de poner más atención a las tareas de gestión y administración en la medida que se empezaron a gestionar los dineros de las ventas, manejar cuentas bancarias, realizar pagos, expedir cheques, así como organizar el acopio en las distintas regiones, enviar el producto al beneficio seco, contratar el transporte al puerto, etc. Si bien estas tareas eran apoyadas por Guayacán — sobre todo en aspectos como la capacitación, gestión y organización de los embarques del café-, se situaba así a la cooperativa en otro nivel de responsabilidades más allá de simplemente representar a los productores.

La participación de YTK en el modelo de comercio justo también implicaría relacionarse con las contrapartes, principalmente con los colectivos de Italia y Alemania, así como con ong locales y nacionales como Granito de Café, a los que vendían algunos remanentes que quedaban de la exportación y los llamados "desmanches". De la misma forma, la mesa directiva de la cooperativa tuvo que profundizar en el tema de la revisión de los contratos y sus condiciones: prefinanciamiento, precio, calidad, tiempo y modalidad de embarque, envío de muestras, "premio social", entre otros.

De esta manera, en su trayectoria de 10 años, YTK había logrado tener incidencia en los varios eslabones de la cadena del café: En el nivel de la producción primaria, se llevó a cabo la conversión de cafetales al incorporar y asimilar los métodos y técnicas orgánicas en la mayor parte de las unidades productivas. Se realizó el acopio, almacenamiento y transporte del grano, así como la construcción de cinco bodegas regionales y de la bodega central en 
Altamirano. De igual manera, la cooperativa realizó el procesado y selección del café pergamino en instalaciones propias —-beneficio seco- - Se inició el proceso de control de calidad mediante la instalación de un laboratorio de catación, y se llevó a cabo el procesado para la venta nacional de café tostado y molido y en taza. Para fines de exportación, la cooperativa obtuvo el registro de exportador en el año 2002 ante Comcafé — hoy Amecafé, Asociación Mexicana de la Cadena Productiva del Café-, asimismo la certificación externa de la producción, del procesamiento — beneficio seco-y de la comercialización por parte de Certimex. Por último, le fue posible acceder a la apertura de esquemas de financiamiento — capital de trabajo para el acopio— a través del consorcio italiano Etimos.

En resumen, la cooperativa había llegado a establecer trato directo con compradores-consumidores. En otro sentido, mediante su inserción en el sistema de comercio justo, la cooperativa logró retener, hasta el año 2009, aproximadamente $24 \%$ del valor final, ${ }^{15}$ no obstante que se reduce a $18 \mathrm{o}$ $20 \%{ }^{16}$ en el nivel de las unidades domésticas debido a los gastos de acopio y operación.

\footnotetext{
${ }^{15}$ ¿Quiénes somos? El colectivo Café Libertad. Informe de Café Libertad Kollective eG. Noviembre 2009.

${ }^{16}$ En promedio, la cooperativa ha liquidado a sus socios $20 \%$ del valor del contrato por $\mathrm{kg}$ de café pergamino. Los precios de los contratos se establecen en volúmenes de café oro o verde seleccionado, mientras al productor se le liquida por kg de café pergamino entregado.
} 


\section{YTK en la autonomía y la resistencia zapatistas. La formación de los Caracoles y las Juntas de Buen Gobierno}

Cuando se daban los pasos para estructurar y dar forma a los esfuerzos organizativos de YTK — incluyendo la conversión orgánica de la producción-, ya se habían observado cambios en las estrategias del movimiento zapatista, pues desde el mes de agosto de 2003 la dirigencia del EZLN anunciaba la transformación de los "Aguascalientes" en unas estructuras territoriales y de gobierno a las que denominó "Caracoles", dentro de las que se integraron los 38 municipios autónomos, dividiéndolos a su vez en cinco regiones políticoadministrativas dotadas de una estructura de gobierno civil denominada Junta de Buen Gobierno.

Estos cambios, que buscaban consolidar los procesos de autonomía en los territorios zapatistas, habrían de conducir a un mayor control de las iniciativas de los municipios autónomos o de algunos sectores de la población de base, y también a una mayor regulación sobre el funcionamiento de los organismos de solidaridad que venían colaborando con apoyos materiales o proyectos específicos destinados a una comunidad o sector dentro de los espacios zapatistas. Esto tendría repercusiones en el posterior desenvolvimiento de YTK, ya que la actuación de la cooperativa debería conducirse bajo los criterios establecidos por las nuevas autoridades — correspondientes a la JBG - e implicaría, como discutiremos más adelante, la pérdida paulatina de condiciones para su autogestión. 
En tanto que estas cooperativas de café — cuando menos en el caso de Mut Vitz- fueron consideradas "como expresión orgánica del movimiento" zapatista (Gerber, 2004), a lo largo de su desarrollo se han visto intervenidas por parte de las autoridades autónomas, ya sea para mediar o conciliar posturas a su interior, o bien para tomar decisiones más directamente sobre su vida interna; esto último se ha hecho más visible desde la creación de las JBG en 2003. Se persigue, mediante esta injerencia, que las cooperativas de café no se desprendan de los criterios de subordinación a la autoridad y que no lleguen a alcanzar una diferenciación económica respecto al resto de las comunidades de base que no cultivan café.

Y en lo que toca al caso de YTK, este nuevo esquema representó una mayor intervención por parte de las autoridades de la JBG — la sede del "Caracol" 4 y de la JBG se habría de establecer en la localidad de Morelia, lugar donde funcionaba el antiguo Aguascalientes - en los asuntos y actividades de la cooperativa, quitándole en los hechos los márgenes de autonomía con los que venía operando.

Dentro del contexto de la autonomía zapatista, el desempeño de la cooperativa YTK se ve constreñido al estar inmersa en las estrategias que señala la resistencia zapatista, y que le impiden, por ejemplo, relacionarse con las agencias oficiales del gobierno. En este sentido las políticas públicas oficiales para la planeación del desarrollo rural y en particular para el sector cafetalero, ${ }^{17}$

\footnotetext{
${ }^{17}$ Programas de fomento productivo, inscripción en el padrón cafetalero, apoyos para la certificación orgánica y para renovación de cafetales, coberturas de precios, combate de plagas, etcétera.
} 
por ejemplo, sólo llegan a tener repercusiones en el funcionamiento de la cooperativa por omisión. Mientras la mayoría de las experiencias cooperativas cafetaleras de Chiapas — y de otras entidades—, igualmente integradas por pequeños productores indígenas, no dudan en establecer relaciones con los aparatos institucionales del Estado para obtener apoyos, proyectos y/o financiamiento, combinándolos con estrategias que apelan a la cooperación solidaria de organizaciones civiles; las asociaciones zapatistas se niegan a recurrir a los apoyos y "limosnas del mal gobierno".

Lo que se observa con el recurso y el discurso de la resistencia en la práctica zapatista de los últimos años es que se da en un contexto que no es el mismo que prevalecía hasta el año 2001 — caracterizado todavía por la atención de vastos sectores sociales y de los medios de comunicación en la evolución del zapatismo-, cuando se repliega el movimiento a sus territorios chiapanecos en la "zona de conflicto". Hacia el año 2003, cuando se crean los caracoles y las Juntas de Buen Gobierno, ya habían cambiado las condiciones en que se desarrollaba el escenario nacional y local, y “...el EZLN [había] dejado de ser el epicentro de la política nacional", ${ }^{18}$ sin que esto implicara, ni de lejos, aproximarse a solucionar las causas que dieron origen al conflicto armado de 1994.

A más de 10 años de la insurrección armada, varios grupos e individuos afiliados al zapatismo se preguntaban si la resistencia era para siempre. ${ }^{19}$

\footnotetext{
${ }^{18}$ Carlos Fazio, en Red Voltaire, http://www.redvoltaire.net/

${ }^{19}$ Van der Haar, Gemma, 2004, "Autonomía a ras de la tierra: algunas implicaciones y dilemas de la autonomía zapatista en la práctica”.
} 
Asimismo, algunos reclamaban acciones por parte de las JBG que dieran respuesta a sus necesidades materiales y de bienestar que no veían llegar. La cooperación internacional había disminuido significativamente, en contraste con la que se observó durante los primeros años posteriores al levantamiento; en tanto que no había estrategias eficaces para impulsar una economía alternativa, ${ }^{20}$ lo que había generado, paradójicamente, dependencia hacia los apoyos de la cooperación solidaria. La suma de todos estos elementos disminuyó el consenso activo a favor de la resistencia, y condujo a que se acentuaran los mecanismos de coerción sobre la población simpatizante.

De lo anterior dejan constancia nuestras observaciones, así como varios testimonios y relatos de socios y representantes regionales de la cooperativa YTK, la que en su relación con las autoridades de la JBG veía disminuir paulatinamente su margen de acción por la creciente intervención de esta estructura en la vida interna de la cooperativa. Estas nuevas políticas se habrían de resentir también en otras cooperativas zapatistas que operaban en la jurisdicción del Caracol de Oventic, como en el caso de Mut Vitz, en el que "la autonomía de [la] organización fue claramente recortada" (Gerber, 2005: 279).

\footnotetext{
${ }^{20}$ Velasco Yáñez, David. 2000, ¿"Hay una economía zapatista?”, en La Otra campaña y las alternativas al neoliberalismo.
} 


\section{Conclusiones}

Hemos revisado en este trabajo algunas de las formas y modalidades con que los diversos agentes que se relacionan con la cooperativa ponen en juego y movilizan sus recursos a partir de su posición en torno al zapatismo, haciendo uso de diversas estrategias para mantener su viabilidad como instituciones de la "sociedad civil". Junto con ello hemos mostrado también cómo, desde el ámbito del autogobierno del Caracol 4, se recurría a sus atribuciones de autoridad para hacer prevalecer las disposiciones emanadas desde la dirigencia zapatista, tanto en sus relaciones internas como con esa "sociedad civil"; tal ejercicio de autoridad es instrumentado al modo en que los representantes de la JBG interpretan las mencionadas disposiciones y principios zapatistas, mediante el conjunto de “...intuiciones del 'sentido práctico'” (Bourdieu, 1996: 22-24).

Es así como la trayectoria de YTK, en el contexto de la experiencia regional de la autonomía en el Caracol 4, no se podría entender sin la intervención y mediación de diversos agentes externos — la sociedad civil—, que han sido atraídos por este "campo de fuerza" que es el movimiento neozapatista.

Es de destacar también que en el proceso se fueron creando las bases para institucionalizar dichos espacios, mediante las cuales los diversos agentes —ong, colectivos de solidaridad, autoridades y mandos zapatistas - perseguían dinamizar y dirigir las prácticas sociales y políticas, y al mismo tiempo 
hacer prevalecer sus estrategias de reproducción o cambio, es decir, para conservar $\mathrm{u}$ obtener posiciones e influencias en torno a la cooperativa YTK. Tal proceso giró alrededor de un discurso del zapatismo sobre el papel, de alcances y relaciones con la sociedad civil y con la sociedad política, discurso que se ha modificado y actualizado de acuerdo con las coyunturas políticas y estrategias del movimiento y que incluyó, por ejemplo, pactar con el gobierno de Chiapas, presidido por Pablo Salazar Mendiguchía, en el periodo 2000-2006 (Villafuerte, 2006: 245).

Todo lo anterior ha repercutido en la intensidad y los modos con que el zapatismo ha establecido sus relaciones y alianzas con la sociedad civil a lo largo de estos 20 años, resultando que, para fines prácticos — pragmáticos—, la sociedad civil se convirtió finalmente en aquellos grupos y sectores simpatizantes, adherentes y/o militantes incondicionales de la causa zapatista, que no cuestionaban sus estrategias ni sus prácticas. Al efectuar este tipo de codificación ${ }^{21}$ o clasificación quedarían al margen aquellos grupos que disentían, pues serían etiquetados como antizapatistas, priístas, paramilitares, "terceristas”, etcétera.

Durante el acompañamiento de las actividades de la cooperativa hemos podido observar diversas prácticas que parecían contravenir el discurso y la propuesta política del zapatismo para con su base social, en particular en el tema de las relaciones entre las comunidades y las autoridades, y en las formas de participación democrática horizontal, "desde abajo", mediante la cual se ${ }^{21}$ Los esquemas clasificatorios y "La codificación es una puesta en orden simbólica, o de mantenimiento del orden simbólico...” (Bourdieu, 1996: 86). 
pretende "la construcción de una 'nueva cultura del poder' ” (Fazio, 2004). Se trata de expresiones en las que también se entreveran elementos "culturales" con nuevas formas de organización social y técnica que se propugnan en virtud de las relaciones de la población con las estructuras y reglas zapatistas y con la sociedad civil.

Vemos de esta manera como, a partir de la creación de los Caracoles y las JBG, se profundizó el proceso de institucionalización de la resistencia zapatista, generándose ciertas estructuras, relaciones y prácticas de coerción para tratar de asegurar la conservación y reproducción del nuevo orden social. De allí que en el proceso zapatista no haya sido explicitado el "sujeto" social de la autonomía, prevaleciendo, en la práctica, la preponderancia de "lo colectivo" por sobre el individuo, la unidad doméstica, y/o los sectores específicos como es la propia cooperativa YTK.

Desde nuestra experiencia, y tomando en cuenta la perspectiva utilizada, en el proceso del neozapatismo consideramos inadecuadas las visiones dicotómicas que contraponen lo individual con lo colectivo, por lo que sería deseable incorporar las distintas dimensiones del cuerpo social y otorgar el mismo valor a las iniciativas individuales y sectoriales facilitando — no inhibiendo- la expansión de las mismas.

Es posible, entonces, ver este proceso como la conformación del espacio social dentro del que se desenvuelve la cooperativa YTK, es decir, aquel constituido por agentes que poseen desiguales posiciones de poder: los mandos militares del EZLN, las autoridades rotativas de la JBG, las asambleas 
de zona, los consejos municipales autónomos, las comunidades, grupos y bases de apoyo, etc., que interactúan dentro de una demarcación física —el territorio del Caracol- Dentro de ese espacio social y territorial se adoptan diversas estrategias de reproducción y de lucha por parte de los agentes que se mueven en él, y se ponen en juego los mecanismos que tienden a reproducir o a transformar dicho espacio, incluyendo, en ocasiones, las formas de apremio que se ejercen desde las posiciones dominantes.

Es inevitable plantearse la reflexión de si en un movimiento que persigue la autonomía política y territorial caben expresiones de autonomías o de autogestión en otras escalas del espacio social. Si en tal proceso debe centralizarse la gestión territorial y de gobierno, o bien, propiciar la reproducción microsocial de las aspiraciones autonómicas. En este sentido, lo que hemos observado son señales muy claras de que la estrategia zapatista se orienta hacia la primera opción, rechazando en la práctica la posibilidad de que iniciativas con potencial autogestivo, como YTK, se desarrollen, en aras de sostener objetivos estratégicos más amplios, como mantener la resistencia, por eso se les mira con recelo y como amenazas a la integridad del movimiento.

Si la "construcción de ciudadanía" (Harvey, 2000: 34) es uno de los principios éticos del zapatismo, consideramos que debería de ser estimulada en todos los niveles del espacio social; refugiarse en el asambleísmo a mano alzada, como en las asambleas de "zona" que se llevan a cabo en los Caracoles, conlleva el riesgo de inhibir la abierta deliberación y la construcción de consensos, así como el de tomar decisiones insuficientemente informadas y reflexionadas. 
La democracia horizontal que practica el zapatismo es contradictoria, obedece a las estrategias de los agentes con mayor poder dentro de ese espacio y no se propicia en todos sus sectores, como lo hemos descrito en el caso de YTK; mientras el sistema de turnos de la JBG recambia periódicamente a sus autoridades, en la mesa directiva de YTK se avala la permanencia de sus representantes más tiempo de lo estipulado y al mismo tiempo se coarta la participación de su base social.

No obstante que hay un esfuerzo por "civilizar" —esto es, transferir las decisiones de lo militar a lo civil— las funciones de gobierno en las nuevas instituciones de la JBG, todavía se observa un predominio muy marcado en la orientación y en la toma de decisiones dentro de estos espacios por parte de los mandos regionales de la estructura militar, lo que reproduce un sistema de relaciones clientelares y paternalistas que también se transminan al funcionamiento de Yochin Tayel Kinal.

Coincidimos en la idea de que la estrategia de la autonomía se construye como una legítima reivindicación social que responde y resiste frente a un Estado inoperante, excluyente y omiso, sin embargo es poco viable sin que se le estimule y se generen las condiciones para su reproducción en todos los niveles y sectores de la población, ya que no “...es posible una autogestión que no sea social ni generalizada" (Almeyra, 2006: 267). 


\section{Bibliografía citada}

Almeyra, Guillermo, 2006, "Avatares de la autonomía en los municipios y comunidades indígenas", en Beatriz Canabal Cristiani et al. (coords.), Diversidad rural. Estrategias económicas y procesos culturales, Universidad Autónoma Metropolitana, Plaza y Valdés editores, México, D. F.

Bermejo, Roberto, 1999, "Realidades y tendencias del comercio justo", Cuadernos Bakeaz, núm. 33, junio de 1999.

Boron, Atilio, 2001, "La selva y la polis. Interrogantes en torno a la teoría política del zapatismo", en Revista Chiapas, núm. 12, ERA, México.

Bourdieu, Pierre, 1996, Cosas Dichas, Gedisa, Barcelona, España.

Bourdieu, Pierre, 1997 [1994], Razones prácticas. Sobre la teoría de la acción, Ed. Anagrama, Barcelona, España.

Bourdieu, Pierre y Loic J.D. Wacquant, 1995, Respuestas por una antropología reflexiva, Editorial Grijalvo, México, D. F.

Cardozo, Fernando H, y Enzo Falettom, 2002 [1969], Dependencia y desarrollo en América Latina, Siglo XXI, México.

Fazio, Carlos, 2004, "México: Resistencia y autonomía. Una década de zapatismo", Red Voltaire, en http://www.redvoltaire.net, descargado de CedoZ.org [fecha de consulta: 18 de octubre de 2011].

Gerber, Philipp, 2004, “'Preguntando caminos'. Café orgánico zapatista: Los tzotziles de la cooperativa Mut Vitz en su caminar autónomo”, en Anuario de Estudios Indigenas X, Instituto de Estudios Indígenas, Universidad Autónoma de Chiapas, México, pp. 247-300.

Harvey, Neil, 2000, La rebelión de Chiapas. La lucha por la tierra y la democracia, ERA, México, D. F.

Molina Valencia, Nelson. 2004, Resistencia comunitaria y transformación de conflictos: un análisis desde el conflicto político armado de Colombia, tesis de doctorado en psicología social, Universidad de Barcelona, Barcelona.

Montañez Gómez, Gustavo y Ovidio Delgado Maheca, 1998, "Espacio, Territorio y Región: Conceptos Básicos para un Proyecto Nacional”, Revista del Departamento de Geografía de la Universidad Nacional de Colombia, vol. VII, núm. 12, Santa Fe de Bogotá, Colombia. 
Ochoa González, Óscar, 2003, “Conversando sobre Gramsci, sociedad civil y hegemonía”, Centro de Investigación y Desarrollo de la Cultura Juan Marinelo, La Habana, Cuba, en http://www.archivochile.com/Ideas_ Autores/gramscia/s/gramscisobre0015.pdf [fecha de consulta: 18 de noviembre de 2011]

Organización Internacional del Café, International Coffee Organization (ICO), disponible en http://www.ico.org/

Renard, Ma. Cristina, 1999, Los intersticios de la globalización. Un label (Max Havellar) para los pequeños productores de café, CEMCA, Embajada del reino de los Países Bajos, ISMAM, México.

Van der Haar, Gemma, 2004, "Autonomía a ras de la tierra: algunas implicaciones y dilemas de la autonomía zapatista en la práctica”, en Pérez Ruiz, Maya Lorena (coord.), Tejiendo historias: Tierra, género y poder en Chiapas, Instituto Nacional de Antropología e Historia, México, D. F.

Velasco Yánez, David, “¿Hay una economía zapatista?”, La Otra campaña y las alternativas al neoliberalismo, en http://www.sjsocial.org/crt/ articulos/753_david_v.html [fecha de consulta: 27 de mayo de 2009].

Villafuerte Solís, Daniel y José Montero Solano, 2006, Chiapas: La voz de los actores, Unicach, Ediciones Casa Juan Pablos, México, D. F. 
Mapa. Zona de influencia de Yochin Tayel Kinal, municipios autónomos y oficiales

\section{Estado de Chiapas}

MUNICIPIOS CON PRODUCTORES DE CAFÉ DE YOCHIN TAYEL KINAL S. P. R. DER. I.

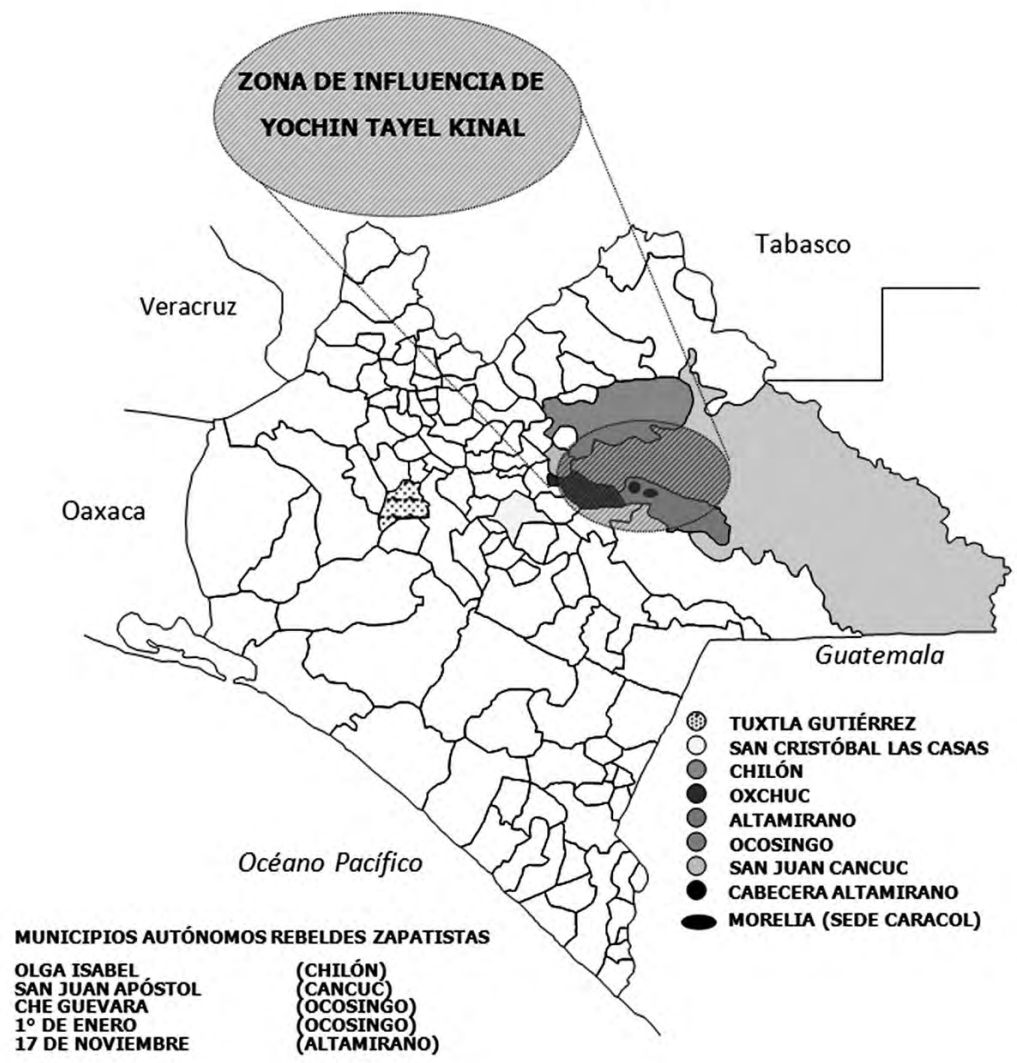

Fuente: Elaboración propia. 